Berkala Ilmu Perpustakaan dan Informasi, Vol. 14, No. 2, Desember 2018, Hal. 133-147 DOI: 10.22146/bip.32920

ISSN 1693-7740 (Print), ISSN 2477-0361 (Online)

Tersedia online di https://jurnal.ugm.ac.id/bip

\title{
Era baru publikasi di Indonesia: status jurnal open access di Directory of Open Access Journal (DOAJ)
}

\author{
Dasapta Erwin Irawan ${ }^{1 *}$, Juneman Abraham ${ }^{2}$, Mochammad Tanzil Multazam ${ }^{3}$, Cut Novianti \\ Rachmi $^{4}$, Indrya Mulyaningsih ${ }^{5}$, Sparisoma Viridi ${ }^{1}$, Rino R. Mukti ${ }^{1}$, Mitra Djamal ${ }^{1}$, dan Deny \\ Juanda Puradimaja ${ }^{1}$ \\ ${ }^{1}$ Institut Teknologi Bandung \\ ${ }^{2}$ Jurusan Psikologi, Universitas Bina Nusantara \\ ${ }^{3}$ Fakultas Hukum, Universitas Muhammadiyah Sidoarjo \\ ${ }^{4}$ Fakultas Kedokteran, Universitas Padjadjaran \\ ${ }^{5}$ Prodi Tadris Bahasa Indonesia, IAIN Syekh Nurjati Cirebon \\ Email: dasaptaerwin@outlook.co.id
}

\section{Naskah diterima: 30 Januari 2018, direvisi: 16 Juli 2018, disetujui: 6 Agustus 2018}

\begin{abstract}
ABSTRAK
Pendahuluan. Kualitas jurnal di Indonesia banyak dikritik, padahal jumlah jurnal Indonesia yang memenuhi kriteria Directory of Open Access Journal (DOAJ) cukup banyak. Studi ini menggambarkan berbagai fakta tentang dunia publikasi di Indonesia berdasarkan data DOAJ dan Bank Dunia.

Metode penelitian. Proses penyaringan data dilakukan pada basis data DOAJ untuk memunculkan jumlah, distribusi bidang ilmu, dan biaya proses artikel (APC) jurnal. Data terbuka dari Bank Dunia tentang dana riset pada berbagai negara turut dianalisis.

Analisis data. Studi ini menggunakan desain kuantitatif-deskriptif dengan analisis frekuensi. Visualisasi data dilakukan dengan menggunakan peranti lunak R Statistical Computing dan Google Sheets.

Hasil dan Pembahasan. Pada Maret 2017, sebanyak 500 jurnal (peringkat ke-5 di dunia) berasal dari Indonesia, 420 diantaranya menggunakan Bahasa Indonesia dengan lebih dari 51.000 artikel (peringkat ke-7) dengan tiga bidang teratas: pendidikan, agama Islam, serta bisnis dan perdagangan. Sebanyak $70 \%$ jurnal tersebut menerbitkan artikel dengan tanpa biaya APC. Ilmu pengetahuan harus inklusif dan setara dengan modal utama orisinalitas dan kejujuran.

Kesimpulan dan Saran. Studi ini menyimpulkan bahwa jurnal-jurnal dengan akses terbuka di Indonesia telah, sedang, dan akan terus meningkatkan aksesibilitas, mutu, dan relevansi riset di Indonesia, yang dapat dinikmati oleh masyarakat, industri, dan pemerintah.
\end{abstract}

Kata Kunci: DOAJ; Akses terbuka; Indonesia; Publikasi

\section{ABSTRACT}

Introduction. The quality of journals in Indonesia is much criticized; however, the number of Indonesian journals that meet the criteria of Directory of Open Access Journal (DOAJ) is quite a lot. This study describes some facts of Indonesia's publications based on DOAJ and World Bank data.

Data Collection Method. Some filtering processes in DOAJ database were done based on sum of journals, scientific fields distribution, and Article Processing Charge (APC). Open data regarding research funds among countries in World Bank database were analyzed.

Data Analysis. This study used quantitative-descriptive design with frequency analysis technique. Data visualization was done with R Statistical Computing and Google Sheets.

Results and Discussions. In March 2017, there were 500 Indonesian journals (5th rank worldwide); 420 of them were in Indonesian covering more than 51,000 articles (7th rank). The top three fields were: education, Islam 
religion, as well as business and commerce. As much as $70 \%$ of the journals were free of APC. Science must prioritize inclusiveness and equality inline with the principles of originality and honesty.

Conclusions. This study concludes that open access journals in Indonesia improves the accessibility, quality, and relevance of Indonesian research, which can be reused by communities, industries, and the government.

Keywords: DOAJ; Open access; Indonesia; Publication

\section{A. PENDAhULUAN}

Menyoroti fenomena Permenristekdikti No 20/2017 yang menghangat akhir-akhir ini dengan pro dan kontranya, sebenarnya tuntutan publikasi di negara berkembang telah terlihat, seperti tertulis dalam publikasi Butler (2013). Banyak pihak yang hanya memberikan komentar mengenai kurangnya kualitas jurnal di Indonesia (Nashihuddin \& Aulianto, 2016). Namun demikian, jurnal Indonesia bahkan yang berbahasa Indonesia telah dikelola dengan baik, sehingga terindeks dalam Directory of Open Access Journal (DOAJ). Jadi quote bahwa Indonesia adalah surganya jurnal open access (OA) tidaklah berlebihan, terutama bila dibandingkan dengan kondisi di negara atau benua lain.

DOAJ digunakan karena lembaga ini bersifat independen dan not for profit (seperti tertayang pada laman resminya), untuk menghindari bias, agar para pemangku kepentingan mengerti kondisi jurnal di Indonesia dari sisi kuantitas untuk menentukan kebijakan yang diperlukan untuk pengembangannya. Data dapat diunduh di repositori Zenodo (Irawan et al., 2017).

Data terbuka internasional, DOAJ dan Bank Dunia, dianalisis secara statistik. Penggabungan kedua basis data ini belum pernah dilakukan untuk menelaah kondisi publikasi di Indonesia. Tujuannya untuk dapat memotret kondisi dunia publikasi ilmiah di Indonesia melalui basis data terbuka, bukan basis data tertutup, seperti Scopus atau Web of Science, yang selama ini sering dilakukan (Irawan et al., 2017).

\section{B. TINJAUAN PUSTAKA \\ 1. Tentang open access}

Gerakan OA hendaknya dapat dilihat bukan semata-mata sebagai gerakan berbasis teknologi, gerakan sistem informasi, ataupun gerakan manajemen, melainkan merupakan sebuah gerakan kemanusiaan dan keperilakuan yang percaya pada kebaikan sebagai kekuatan dasar dari manusia. Hal ini kompatibel dengan pendekatan "sumber terbuka" (open source) yang lebih dahulu populer di Indonesia, yang sangat sejalan dengan pendekatan psikologi positif (Juneman, 2009). Keterbukaan (openness) ternyata berhubungan dengan kebijaksanaan, kehidupan yang otentik, serta sikap pro-lingkungan (Abraham \&Wirayudha, 2015). Penulis menduga metrik berdasarkan indeksasi terbuka secara signifikan dapat berbeda dari metrik berdasarkan indeksasi tertutup, meskipun hal ini memerlukan penelitian lebih lanjut. Dugaan ini memiliki dasar dalam wacana sehari-hari (Modi, 2014). Apakah kita sebagai masyarakat Indonesia, ASEAN, dan Asia akan turut masuk dalam siklus ini? Jelas, masyarakat Indonesia yang merupakan faktor utama yang mampu memilih untuk memberdayakan diri sendiri ataukah, sebaliknya, larut dalam ketidakberdayaan.

\section{Kondisi OA di berbagai negara}

Open access (OA) sendiri pada dasarnya adalah gerakan membangun kesadaran bagi para peneliti/penulis/akademia pada umumnya untuk melakukan pengarsipan secara mandiri (self-archiving) serta membuka aksesnya seluas mungkin, serta mempublikasikan karya ilmiahnya pada jurnal OA, yakni jurnal yang membebankan biaya publikasi dari sumbersumber lain selain biaya langganan (subscription) dari pembaca. Biaya publikasi dapat berasal dari penulis dengan membayar article processing charge (APC), donasi atau sponsorship dari lembaga (Bailey, 2006; Tennant \& Mounce, 2015). Diagram Tennant 
dan Matthias (2017) memperlihatkan bagaimana agar karya kita dapat $100 \%$ bersifat OA.

Sebagai pendahuluan, berikut ini grafik jumlah jurnal OA pada berbagai negara (top 50) yang ada dalam pangkalan data DOAJ (Gambar 1; Irawan, 2017a). Indonesia berada pada urutan no 5 dengan jumlah jurnal terbanyak yang diindeks oleh DOAJ, setelah Brazil, UK, AS, dan Mesir. Di bawah Indonesia berikutnya Spanyol, Polandia, Jerman, Rumania, Iran, Italia, dan India. Perkembangannya jurnal OA menjadi pesaing jurnal non-OA. Dari sisi jumlahnya pun terus bertambah tiap tahun. Bila kita memperhatikan laporan Confederation of Open Access Repositories (Shearer, Yamaji, \& Repanas, 2016) dan Irawan (2017b), belum ada repositori yang secara resmi terdaftar dari Indonesia.

Berdasarkan data Bank Dunia, jumlah artikel total dari beberapa negara terlihat seperti pada Gambar 2. Terlihat bahwa Jepang memimpin, disusul oleh Brazil, Malaysia, Mesir, Indonesia, Sudan, dan Kamboja. Jepang mengalami lonjakan jumlah publikasi menjelang tahun 2000. Demikian pula Brazil, di kawasan Asia Tenggara, Malaysia memimpin. Lonjakannya terjadi di pertengahan 2005-2010. Kondisi tersebut berhubungan dengan grafik persentase belanja riset dan pengembangan $(R / D)$ di tiap negara tersebut (Gambar 3), dengan Jepang masih di urutan teratas. Selanjutnya ada yang menarik pada Gambar 4 dan Gambar 5, dapat dilihat bahwa jumlah artikel berhubungan positif dengan persentase dana riset dan pengembangan yang dianggarkan dalam suatu negara. Khusus untuk Jepang, belum dapat disimpulkan apakah kondisi yang sama juga berlaku berdasarkan hasil plot yang menunjukkan dua pola. Proporsi jumlah peneliti pada tiap 1000 penduduk juga menunjukkan adanya keterkaitan dengan jumlah anggaran $\mathrm{R} / \mathrm{D}$. Secara tidak langsung, hal ini berarti bahwa penduduk merespon positif secara cepat terhadap jumlah anggaran R/D. Bila anggaran naik, maka jumlah peneliti akan naik, dan begitu pula sebaliknya. Namun apakah ini berkaitan dengan jumlah universitas di tiap negara, perlu ditelaah lebih lanjut.

\section{METODE PENELITIAN}

Kajian ini memperlihatkan analisis statistik sederhana terhadap data primer terbuka (primary open data) yang selama ini banyak tersedia secara daring tapi tidak banyak diketahui oleh para peneliti Indonesia (Rahim et al., 2018). Desain analisis yang digunakan adalah kuantitatif-deskriptif dengan analisis frekuensi yang dilengkapi dengan visualisasi grafis menggunakan peranti lunak $R$ Statistical Computing dan Google Sheetsterhadap data primer terbuka (primary open data) dari h t t p s : / / d o a j.org/ d a n https://data.worldbank.org/.

Analisis yang dilakukan dalam kajian ini mayoritas berbasis data dari DOAJ yang tercantum dalam laman resminya. Data yang digunakan data jurnal open access (OA) yang dihimpun oleh DOAJ. Analisis dilakukan pada tanggal 11 Maret 2017 dengan menggunakan filter sebagai berikut: 'Search type': Journal, 'Country of publisher': Indonesia, 'Full text language': Indonesia.

Walaupun pencarian dilakukan pada bulan Maret 2017, tapi dinilai angka-angkanya masih proporsional dengan banyaknya perkembangan tentang open access di Indonesia. DOAJ merilis pernyataan melalui akun Twitter-nya (https://twitter.com/DOAJplus/status/9267899 94454269952), tanggal 4 November 2017, bahwa jumlah permintaan untuk pengindeksan dari jurnal Indonesia naik 111\% dari tahun 2016. Hal ini merupakan bukti lain peningkatan kesadaran jurnal Indonesia untuk bersaing mencapai standar internasional yang berbasis komunitas, bukan entitas komersial. Hasil pencarian kemudian ditabelkan berdasarkan: institusi penerbit, bidang ilmu, status article processing charge (APC), dan tahun diindeks dalam DOAJ.

Pada pencarian tahap kedua, digunakan filter 'Search type': Articles. Selain itu data bank Dunia (World Bank) juga digunakan untuk memadukan indikator saintifik dengan indikator makro sebuah negara; salah satunya yakni persentase anggaran riset dan pengembangan (Research and Development / RnD) dibandingkan GDP total. Penulis berinisiasi menghubungkan, untuk membandingkan 
berbagai fenomena menarik tentang publikasi ilmiah atau dunia saintifik yang mungkin didapatkan pada berbagai negara dengan berbagai kondisi ekonomi.

\section{HASIL DAN PEMBAHASAN \\ 1. Distribusi jurnal \\ 1.1 Berdasarkan institusi penerbit}

Hasil yang diperoleh sebanyak 25 penerbit jurnal teratas yang mencakup heterogenitas bidang ilmu yang ada di Indonesia. Walaupun kurang lebih $60 \%$ dari penerbit tersebut ada di Pulau Jawa, dipimpin oleh Universitas Negeri Semarang, tapi sudah mulai muncul penerbit dari Banda Aceh, Madura, Samarinda, dan lainlain. Iklim ini dinilai sangat baik (Gambar 6). Aktivitas komunitas Relawan Jurnal Indonesia cukup agresif untuk menyosialisasikan manajemen jurnal yang baik serta peranti lunak Open Journal System(OJS).

\subsection{Berdasarkan bidang ilmu}

Peneliti hanya menampilkan daftar 25 bidang ilmu teratas (Gambar 7). Bidang ilmu paling banyak pendidikan secara umum (education in general). Kedua tentang Agama Islam, dan ketiga tentang bisnis dan perdagangan (business and commerce). Gap yang cukup besar terjadi untuk bidang geografi dan ilmu lingkungan yang ada di urutan bawah. Bidang ilmu ini diduga mencakup juga ilmu geologi, kebumian, dan hidrogeologi, yang belum tertera secara eksplisit dalam klasifikasi jurnal di DOAJ. Dalam hal ini, metadata DOAJ perlu diperbaiki. Namun demikian, di awal Januari 2018, DOAJ telah mengumumkan bahwa mereka merilis tabel basis data jurnal secara berkala. Analisis yang lebih menarik dapat dihasilkan dengan data tersebut.

Hal yang menarik bahwa posisi jurnal dengan bidang ilmu Agama Islam berada pada peringkat kedua. Di sisi lain, banyaknya jumlah jurnal di bidang ini, nampaknya tidak diikuti oleh program pemasaran jurnal yang luas, atau pemasarannya relatif tertutup di antara sivitas akademik dan peneliti di bidang Agama Islam saja.

\subsection{Berdasarkan status Article Processing Charge}

Mayoritas jurnal tidak mengenakan APC, walaupun berstatus jurnal Open Access (OA). Dapat dilihat bahwa lebih banyak jurnal yang tidak mengenakan APC (75,5\%). Sedangkan jurnal yang mengenakan APC pun, biaya maksimumnya Rp 1.500.000,00. Hasil dari komunikasi personal via media sosial dengan pengelola akun Twitter DOAJ dan beberapa penggiat sains terbuka, J. Tennant \& P. Suber, personal communication, terlihat ada trend peningkatan APC yang perlu survey lebih lanjut. Namun demikian, ada beberapa jurnal yang mencantumkan nilai APC yang lebih dari itu. Salah satunya jurnal yang berasal dari bidang kedokteran.

\subsection{Berdasarkan tahun masuk ke DOAJ}

DOAJ menampilkan data sejak tahun 2009, hal ini dapat dilihat bahwa pada 2014 ada peningkatan jumlah jurnal yang diindeks oleh DOAJ. Peristiwa atau kebijakan yang melatarbelakanginya perlu dicari tahu secara rinci, sebagai modal dasar untuk lebih mengembangkan jurnal OA di Indonesia.

\subsection{Jumlah artikel}

Hasil pencarian menunjukkan ada lebih dari 51.000 artikel berbahasa Indonesia yang terdata sejak 1984 hingga 2017. Itu berarti kurang lebih 1500 artikel per tahun. Seluruh artikel tersebut merupakan open access. Angka ini bisa disebut kecil bila dibandingkan dengan jumlah penduduk Indonesia atau jumlah perguruan tinggi dan lembaga riset di Indonesia. Tapi jelas merupakan angka yang tidak sedikit untuk digunakan sebagai pijakan. Jumlah makalah berbahasa Indonesia berada pada peringkat 7 berdasarkan bahasa di basis data DOAJ. Peringkat pertama Bahasa Inggris (2.000.000+) dan yang terakhir adalah Bahasa Spanyol (21.000+). Hal ini merupakan landasan yang cukup untuk membuat pembuat kebijakan di bidang pendidikan mulai mengalihkan perhatiannya dari fokus kepada kriteria-kriteria capaian akademik dunia barat. 
Berkaitan dengan kriteria pengukuran kinerja akademik, bahwa kemudahankemudahan yang ditawarkan oleh metrik yang saat ini dianut, seperti $H$-index, jumlah sitasi, jumlah artikel terindeks, dan sebagainya. Namun demikian, di masa mendatang akan tiba masanya, pihak perguruan tinggi, atau kementerian riset, teknologi dan pendidikan tinggi, menilai kinerja dengan lebih bijak, melihat riset secara utuh, tidak hanya di bagian akhirnya.

\subsection{Dampak jurnal OA bagi pembangunan Indonesia}

Setelah menyimak data di atas, sangat layak bila Indonesia sebagai "surganya jurnal OA". Maraknya jurnal OA di Indonesia, semestinya dampaknya sangat luas (Harnad, 2005). Jurnal OA akan sangat memudahkan akses oleh masyarakat, pemerintah, dan industri, dibandingkan dengan jurnal non-OA(Tennant et al., 2016). Akselerasi sains di kalangan akademia, komersialisasi di kalangan industri/praktisi, dan sosialisasi di kalangan masyarakat lebih mungkin terjadi bila tidak ada batas akses yang mahal. Hal ini hanya akan terjadi bila akses kepada ilmu pengetahuan bersifat cuma-cuma, segera, dan bebas. Dalam hal ini, Pemerintah Indonesia dapat bercermin kepada Pemerintah UK guna memaksimalkan dampak kebebasan akses terhadap hasil riset. Upaya yang dilakukan ini akan menjamin sekaligus meningkatkan pelaksanaan kebebasan akademik (Abraham, 2018) di Indonesia.

Sebuah artikel yang berjudul "OA Impact Advantage" (Harnad, 2005) yang kemudian dirujuk dalam artikel berjudul "Economic Implications of Alternative Scholarly Publishing Models Exploring the Costs and Benefits" (JISC, 2016) menyebutkan enam komponen yang mempengaruhi nilai sebuah produk OA, yakni: (1) early advantage: jurnal OA memiliki peluang dibaca lebih cepat dibanding jurnal non-OA; (2) preprint advantage: keuntungan ini berhubungan dengan pengunggahan jenis publikasi preprint yang diawali oleh komunitas ilmuwan fisika dan matematika. Publikasi jenis preprint ini diklaim memicu percepatan pengembangan dan penyerapan ilmu baru, karena bentuk makalah ini belum melalui peer-review; (3) quality bias: ini juga berkaitan dengan produk makalah berjenis preprint. Karena naskah belum melalui proses peer review, maka punya potensi masalah dalam hal kualitas. Tapi makin banyak penulis mengunggah naskah preprint-nya, maka bias akan terus menurun; (4) quality advantage: dengan OA, maka pembaca memiliki pilihan lebih luas. Mereka bisa menetapkan standar makalah berkualitasnya sendiri. Bila makalah hanya dikeluarkan oleh penerbit non-OA, maka kualitas akan hanya dikendalikan oleh penerbit; (5) competitive advantage: peningkatan jumlah naskah OA, juga dianggap dapat meningkatkan nilai jual atau "competitiveness" individu dan atau institusinya, dan (6) usage advantage: ini berkaitan dengan komponen early advantage. Makalah OA dapat digunakan oleh sebanyak mungkin orang, dan sesering mungkin tanpa batasan jumlah dan waktu.

Selain dampak di atas, gerakan open access dapat berdampak juga kepada dunia kesehatan, penanganan penyakit menular dan berbahaya di negara miskin dan negara berkembang. Penyebaran ilmu di bidang ini harus segera dan cepat serta tidak layak untuk dihalangi dinding pembayaran (Tennant et al., 2016). Untuk itu sangat disarankan agar para pengelola jurnal dan akademia secara umum dari negara-negara ini untuk bergabung dan menggabungkan diri ke dalam organisasi yang kuat agar dikenal dan mempunyai posisi tawar secara internasional.

\section{Beberapa catatan bagi para pengelola jurnal OA}

2.1 Menghindari mengejar indexing dari lembaga komersial sebagai tujuan utama

Saat ini banyak indeksasi yang dapat dipilih, kadangkala juga mengejar indeksasi arus utama, seperti Scopus ataupun Web of Science, para pengelola jurnal sebaiknya agar tidak hanya mengejar salah satu atau keduanya saja. Berikut ini beberapa pertimbangan agar tegas tentang hal ini:

1. Meningkatkan biaya publikasi: Indexing oleh lembaga-lembaga komersial akan menambah komponen biaya yang tidak perlu dalam penerbitan makalah atau jurnal. 
Contoh: saat ini konferensi atau seminar yang terindeks Scopus meminta biaya konferensi (conference fee) rata-rata tidak kurang dari Rp 3.000.000,00. Biaya sebesar itu berat bagi mahasiswa (S1, S2, S3) sebagai komponen akademia yang paling membutuhkan dan juga menjadi penulis.

2. Sering terjadi kesalahan dalam memasang portal paywall (portal pembayaran): Berkaitan dengan butir ke-1, pada beberapa kasus (dan ini sering terjadi), lembaga pengindeks tersebut memasang portal paywall untuk makalah yang semestinya berstatus OA. Bila kita telah membayar biaya publikasi atau disebut juga article processing charge (APC), maka semestinya dokumen kita akan berstatus OA, pembaca tidak akan ditarik biaya.

3. Menambah waktu publikasi: Kalau kita mengejar indeks arus utama, maka makalah yang dipublikasikan harus dalam Bahasa Inggris. Tanpa adanya tim translator dan proof reader, kondisi ini akan menambah durasi proses makalah, yakni di tahap review dan penyuntingan. Maka makalah baru akan dimuat resmi dalam laman indexing ratarata enam sampai delapan bulan sejak pengiriman makalah ke jurnal atau panitia seminar (submission) atau bahkan sejak makalah dipresentasikan dalam seminar.

4. Syarat yang diajukan adalah syarat umum: Sebenarnya syarat yang diajukan oleh kedua lembaga pengindeks tersebut di atas sama dengan syarat yang diajukan oleh lembaga lainnya, misalnya: syarat yang diminta dalam proses akreditasi. Dalam banyak sisi, justru lembaga akreditasi jurnal di Indonesia memiliki syarat lebih banyak dan ketat.

5. Kekhawatiran berlebihan bahwa makalah atau jurnal tidak akan muncul dalam mesin pencari (search engine): Kekhawatiran ini sudah tidak relevan, karena apapun yang sifatnya telah daring (online) dapat dicari oleh bot mesin pencari.

Sampai saat ini, bahkan Google Scholar dan Microsoft Academic pun masih digunakan oleh Pemerintah Indonesia sebagai alat ukur kinerja riset. Bahkan pada akhir ini, kedua indeks terbuka tersebut telah diakui sebagai ciri jurnal bereputasi (Permenristekdikti No. 20/2017, lampiran, dan juknisnya). Anne-Wil Harzing, pembuat peranti lunak Publish or Perish yang menggunakan basis data Google Scholar, menyatakan bahwa Google Scholar menjadi alternatif (pesaing) serius bagi Web of Science (Harzing 2017). Artikel tersebut meluruskan berbagai persepsi yang salah tentang Google Scholar. Lebih ekstrim lagi, ada pandangan yang menyatakan bahwa sains adalah milik komunitas dan masyarakat jadi tidak sepantasnya diatur oleh penerbit eksklusif dengan alasan untuk menjaga kualitas (Bhattacharya, 2017).

Salah satu indexing yang sedang mengemuka yakni indexing oleh ScienceOpen (SO,https://www.scienceopen.com/), sebuah perusahaan yang berbasis di Jerman. SO mengutamakan kerjasama dengan penerbit jurnal OA. Mereka menggunakan Altmetric (https://www.altmetric.com/) sebagai ukuran reputasi atau dampak dari suatu makalah. Selain itu, disarankan juga direkomendasikan bahwa indexing oleh Pubmed Central (PMC, https://www.ncbi.nlm.nih.gov/pmc/), sebuah indeks yang awalnya dibuat untuk bidang ilmu kedokteran dan kesehatan karena basis data itu gratis dan menyediakan data yang lebih rinci dibanding Google Scholar.

\subsection{Inisiatif yang dapat digalang}

Dimulainya inisiatif ASEAN Citation Index (ACI) dapat digunakan sebagai momentum penggalangan kekuatan pengelola jurnal, khususnya jurnal OA, di kawasan ASEAN, yang notabene mayoritasnya negara yang tidak berkomunikasi dalam Bahasa Inggris (nonEnglish speaking countries).

Beberapa hal strategis yang dapat digalang:

1. Memperbaiki kualitas jurnal Indonesia, baik yang berbahasa Indonesia maupun yang berbahasa Inggris.

2. Menguatkan komitmen akademia, tidak hanya untuk secara intensif mempublikasikan karyanya, tapi juga menumbuhkan semangat untuk 
memberikan komentar peer-review yang obyektif dan tepat waktu agar tidak menghambat proses publikasi.

3. Menumbuhkan semangat menulis kepada para mahasiswa dan sejawat akademia muda, misalnya dengan memberikan pelatihan penulisan artikel ilmiah (Viridi \& Yuliarto, 2017).

4. Menggalang kekuatan di antara pengelola jurnal di negara-negara anggota ASEAN melalui ASEAN Citation Index untuk meningkatkan posisi tawar dengan lembaga-lembaga pengindeks internasional. Aktif dalam kegiatan-kegiatan yang diselenggarakan oleh organisasi-organisasi internasional pendukung open science. Status repositori terbuka di Indonesia juga masih tertinggal, bahkan belum direkognisi oleh COAR (Confederation of Open Access Repository) dibanding Malaysia misalnya. Mereka memiliki inisiatif Malaysia Theses Online yang dimulai pada tahun 2016.

Menemukan inovasi-inovasi baru dalam penerbitan jurnal yang mampu menarik minat pembaca dari negara-negara barat untuk membaca makalah dalam Bahasa Indonesia, misal: dengan menerbitkan slide berbahasa Inggris sebagai pendamping makalah dalam Bahasa Indonesia, atau menyisipkan translasi Bahasa Inggris ke dalam bagian-bagian penting naskah dalam Bahasa Indonesia (lihat sub bab selanjutnya). Modal utamanya adalah nilai orisinalitas, yang mana tidak akan sulit bila mengingat kondisi geofisik, lingkungan, dan sosial budaya di Indonesia.

\subsection{Meningkatkan pembaca dari "English speaking countries"}

Salah satu yang menjadi isu besar di Indonesia sebagai non-English speaking country yakni penting atau tidaknya menulis dalam Bahasa Inggris. Kalau menulis dalam Bahasa Inggris masih sulit, dan akhirnya terjebak dalam "jurnal meragukan" agar cepat terbit, mengapa tidak menulis dalam Bahasa Indonesia. Menulis menggunakan Bahasa Ibu, maka riset dapat ditulis dengan sebaik-baiknya, dan dijelaskan dengan sejelas-jelasnya.

Di samping itu, menulis dalam Bahasa Ibu dengan baik mengindikasikan (meskipun bukan satu-satunya) cinta tanah air, karena meningkatkan literasi masyarakat kita sendiri. Ada bagian dari masyarakat kita yang belum tentu ataupun belum berkepentingan memiliki daya akses (finansial, kepustakaan, maupun linguistik) terhadap jurnal-jurnal berbahasa asing. Di samping itu tidak dapat dipungkiri bahwa penciptaan pengetahuan banyak berlangsung dalam situasi tertentu. Realitas pengetahuan bersifat kontekstual. Contoh sederhana: beras, pari, sego, intip, upo, dalam bahasa Jawa; semuanya disebut "rice" dalam bahasa Inggris (Dardjowidjojo, 2007). Kekayaan objektif dan keindahan intersubjektif pengetahuan tidak selalu dapat ditangkap dan diungkap dengan bahasa Inggris.

Lantas bagaimana dengan pembaca dari negara selain Indonesia? Untuk hal ini penulis baru berhipotesis, karena belum pernah melakukan riset secara langsung. Menurut analisa, para pembaca asing pasti akan mencari sebanyak-banyaknya makalah yang relevan dengan subjek dan terutama dengan lokasi risetnya. Setidaknya kondisi tersebut mengarah ke arah bahwa bahasa bukan kendala utama saat peneliti asing mencari referensi yang terkait dengan risetnya (75\% dari 142 responden dari Tweet Poll). Jadi bila mereka akan meneliti di suatu lokasi di Indonesia, mereka sadar bahwa besar kemungkinan harus mencari makalah dalam Bahasa Indonesia. Salah satu yang dapat dilakukan oleh pengelola jurnal berbahasa Indonesia adalah dengan mewajibkan bagi para penulis yang makalahnya telah diterima untuk: (1) membuat slide atau abstrak panjang (extended abstract) berisi gambar-gambar dan tabel dalam Bahasa Inggris untuk menceritakan makalahnya secara singkat; (2) memuat data mentah sebagai lampiran (supplementary electronic data) atau mendorong mereka untuk mengunggah data di repository terbuka seperti OSF, Figshare, atau Zenodo. Bidang ilmu kebumian dapat memanfaatkan server repositori Pangaea; (3) menggunakan judul dan abstrak yang memuat identitas lokasi, setidaknya nama kabupaten dan "Indonesia" (Irawan, 2015); (4) membuat abstrak dalam format video, di mana penulis menceritakan naskahnya dalam Bahasa 
Inggris (baca juga laman The Scientist Videographer, http://thescientist videographer.com/wordpress/how-to-make-avideo-abstract-for-your-next-journal-article/). Hal ini sangat sesuai dengan situasi Indonesia yang masih kental dengan budaya lisan (berbicara) dan merupakan pengguna Live Instagram Video dalam jumlah yang cukup besar. Artinya, kalau minat membuat videovideo media sosial ini tinggi, maka dapat dimanfaatkan untuk membuat abstrak dalam bentuk visual.

Perkembangan saat ini adalah beberapa server preprint (mayoritas yang di-host oleh OSF) telah menerima makalah preprint dalam bahasa selain Bahasa Inggris. Ini merupakan kemajuan signifikan untuk melintasi batasan bahasa (language boundary) dalam dunia saintifik.

\subsection{Menghindari kriteria jurnal meragukan}

Jurnal-jurnal OA dalam pengelolaannya walaupun belum dapat menyamai kinerja jurnal-jurnal berusia dewasa (baca: jurnal lama) di luar negeri tapi hal yang perlu dijaga agar tidak menjadi jurnal yang meragukan (questionable journal). Ini sangat penting mengingat sudah muncul persepsi di dunia internasional bahwa banyak jurnal meragukan diterbitkan di benua Asia (Shen \& Björk, 2015). Sebanyak 38\% jurnal meragukan diterbitkan oleh penerbit dari Asia (India dan non-India) (Shen \& Björk, 2015). Menurut penulis yang sama, distribusi penulisnya $60 \%$ berasal dari Asia (India dan non-India). Terdapat dua kutub dalam hal menetapkan status jurnal apakah "aman" atau meragukan. Kutub pertama yakni pihak-pihak yang bersandar kepada daftar hitam. Untuk ini Daftar Hitam Beall (Beall's list of predatory journal) masih sangat dominan, walaupun lamannya telah non-aktif sejak Januari 2017. Laman tersebut akan dilanjutkan oleh Predatory Journals dan Cabell's Online Directory.

Kutub kedua yakni komunitas yang tidak melihat daftar hitam sebagai sesuatu yang obyektif dan etis, karena itu tidak patut untuk dilanjutkan. Kutub ini bersandar kepada daftar putih (white list) yang telah dipublikasikan oleh beberapa lembaga, misal daftar indeks DOAJ, indeks ScienceOpen, serta direktori-direktori yang dikembangkan oleh penerbit/lembaga besar seperti Scopus dan Web of Science. Cara lainnya dengan melihat kriteria, yang saat ini telah dipopulerkan oleh Komunitas Think CheckSubmit (https://thinkchecksubmit.org/, telah diterjemahkan pula dalam Bahasa Indonesia). Kutub ini melihat bahwa penulis/peneliti semestinya sudah dewasa dan terampil untuk menentukan jurnal yang tepat bagi karya ilmiahnya, karena itu mereka tidak melihat esensi untuk tetap melanjutkan mengembangkan daftar hitam. Berbagai kriteria tersebut diharapkan pemilihan jurnal dapat lebih objektif untuk menghindari jebakan jurnal yang meragukan.

Tahapan evaluasi jurnal inilah yang perlu disosialisasikan secara masif, mengingat masih banyak penulis/peneliti yang tidak mengetahui cara membedakan jurnal yang bertatakelola baik dan jurnal yang hanya mementingkan pemasukan dana APC. Tahapan ini sangat penting juga untuk merespon niat baik pemerintah Indonesia dalam meningkatkan jumlah publikasi internasional melalui pengesahan Permenristekdikti No. 20/2017.

\subsection{Jejaring internasional}

Untuk mendapatkan informasi yang terbaru dan agar jurnal Indonesia tidak cukup hanya terindeks oleh lembaga internasional, tetapi juga perlu berpartisipasi aktif dalam pergaulan jejaring pengelola jurnal secara internasional. Beberapa organisasi di bawah ini sangat bagus untuk dipelajari dan digunakan sebagai standar: Komite standar etika penerbitan, Committee on Publication Ethics; International Association of Scientific, Technical, and Medical Publishers (STM Association of Scholarly Publishers); serta khusus untuk bidang ilmu alam, teknik, dan kedokteran, Preprint initiatives (ASAPbio). Preprint yakni salah satu tradisi yang sedang mengemuka dengan lahirnya beberapa layanan ini di seluruh dunia yang bersifat terbuka dan inklusif (tidak eksklusif untuk artikel dalam Bahasa Inggris), termasuk di dalamnya adalah INArxiv. 
Pengelola jurnal juga perlu mendorong para penulis untuk mempublikasikan komponenkomponen risetnya secara terbuka dengan bekerjasama dengan: (1) Server data, misal: PANGAEA (untuk bidang ilmu alam dan kebumian), Lembaga pengindeks repositori data terbuka (Directory of Open Access Repository, DOAR), Lembaga pengindeks data (Datacite). Repositori Institusi (RI) perlu diperluas aksesnya dan penggunanya agar makin banyak warga universitas yang memahami fungsi RI. Beberapa ketakutan yang sering disampaikan adalah: bahwa RI akan menyebabkan artikel dianggap duplikasi, plagiasi (atau self-plagiarism), dan lain-lain; (2) Server preprint: ArXiv, BioRXiv, OSF Preprints; (3) Server peer-review dan jejaring riset: Publons, PaperHive, Peerage of Science, atau ScienceOpen.

Khusus mengenai peer-review atau biasa disebut penelaahan mitra bestari, para pengelola jurnal dapat memanfaatkan para mahasiswa S3 dari Indonesia yang sedang menuntut ilmu di luar negeri untuk berkontribusi, terutama yang menerima beasiswa dari Pemerintah Indonesia. Mahasiswa ini dapat memanfaatkan ilmunya untuk memberikan komentar orisinal yang konstruktif terhadap berbagai makalah yang masuk ke redaksi.

Selain itu sistem open peer-review juga layak untuk dipertimbangkan, karena akan meningkatkan objektivitas dan kecepatan proses dibandingkan sistem review tertutup (Tennant et al., 2017). Proses identifikasi penulis dan reviewer juga akan lebih mudah bila pengelola jurnal bergabung ke dalam organisasi ORCID dengan mengintegrasikan sistem loginnya (catatan: mayoritas jurnal di Indonesia dikelola dengan peranti lunak berbasis daring Open Journal System/OJS yang dibuat oleh Public Knowledge Project/PKP).

Pemanfatan media sosial dapat dimaksimalkan untuk membina jejaring internasional. Mayoritas akademia, lembaga, perusahaan, dan lembaga swadaya masyarakat yang bergerak di bidang keilmuan menggunakan Twitter untuk menyebarluaskan pemikirannya. Pola komunikasi yang terbuka diantara para akademia telah berubah lebih terbuka. Percakapan via Twitter dapat mengarah kepada kerjasama yang lebih konkret, dibandingkan saluran formal melalui pembuatan nota kesepahaman (MoU) dan sejenisnya.

\section{E. KESIMPULAN}

Jumlah jurnal saintifik yang masif merupakan salah satu kekuatan kita, karena itu kepercayaan diri peneliti Indonesia untuk menuliskan karyanya dalam Bahasa Indonesia harus ditingkatkan untuk dapat menyampaikan pemikiran secara lebih jelas. Upaya internasionalisasi dapat dilakukan dengan membuat artikel dwibahasa atau abstrak panjang atau slide paparan dalam Bahasa Inggris (sebagai pendukung makalah utama). Semangat ini diharapkan dapat meluas dalam lingkup ASEAN. Kementerian Ristekdikti perlu segera memperluas metrik dampak riset yang mengakomodir produk riset dalam Bahasa Indonesia guna menumbuhkan iklim akademik di Indonesia, khususnya untuk peneliti pemula. Kondisi ini juga sangat diperlukan untuk mendorong iklim sains terbuka di Indonesia.

Jumlah jurnal OA nasional yang tinggi di Indonesia adalah salah satu cara untuk mencapai target kinerja yang diatur dalam Permenristekdikti dengan pertimbangan: (1) Komponen jumlah dan bahasa: jumlah artikel yang masif, yang mayoritas ditulis dalam Bahasa Indonesia. Keterbatasan bahasa tidak seharusnya menghambat penulis untuk menghasilkan artikel ilmiah; (2) Komponen orisinalitas substansi: didukung dengan nilai orisinalitas kondisi biogeofisik dan sosialekonomi kawasan tropis. Para penulis perlu lebih percaya diri bahwa artikelnya memiliki nilai plus. Hal ini juga diharapkan meningkatkan kontribusi artikel ilmiah yang ditulis dalam bahasa selain Bahasa Inggris untuk dunia ilmiah; (3) Komponen pendanaan: APC yang rendah bahkan gratis merupakan model pendanaan yang unik karena sebagian besar didukung anggaran lembaga; (4) Komponen peer-review: pengelola jurnal juga dapat berpartisipasi aktif dalam berbagai organisasi penerbitan internasional serta menggalang kerjasama juga dengan komunitas mahasiswa 
S3 yang sedang menuntut ilmu di dalam dan luar negeri sebagai peer-reviewer; (5) Komponen diseminasi: indeksasi dalam hal ini dapat dimaksimalkan dengan mendaftarkan jurnal ke program indeksasi berbasis komunitas dan bersifat nirlaba. Selain itu, media sosial (disarankan Twitter) dapat dijadikan saluran diseminasi baru bagi para pengelola jurnal.

\section{DAFTAR PUSTAKA}

Abraham, J. (2018). Kebebasan akademik: Melanjutkan gagasan psikologi perguruan tinggi. INArxiv. Retrieved April 23, 2018, from https://osf.io/preprints/inarxiv/q5nce/. https://doi.org/10.17605/OSF.IO/Q5NCE.

Abraham, J., \& Wirayudha, M. S. (2015). Personality traits, sedentariness, and personal dilemma as the dynamic predictors of intention to use public transportation in greater Jakarta. Makara Hubs-Asia, 19(2), 125-143. https://doi.org/10.7454/ mssh.v19i2.3481.

Bailey, C. W., Jr. (2006). What is open access? Digital Scholarship. Retrieved April 17, 2017 , from http://digitalscholarship.org/cwb/WhatIsOA.htm.

Bhattacharya, A. (2017). Medical research: The shackles of scientific journals. The Economist. Retrieved April 17, 2017, from http://www.economist.com/news/leaders/2 1719480-and-how-cast-them-shacklesscientific-journals.

Butler, D. (2013). Investigating journals: The dark side of publishing. Nature. Retrieved April 17, 2017 , from http:// www.nature.com/news/investigatingjournals-the-dark-side-of-publishing1.12666.

Dardjowidjojo, S. (2007). Psikolinguistik: Memahami asas pemerolehan bahasa. Jakarta, Indonesia: Yayasan Obor Indonesia. Retrieved from https://books.google.co.id/ books?id=mE-kj4T1JKMC\&printsec $=$ copyright\&hl=id\&source $=g b s \_p u b \_i n f o \_r$.
Harnad, S. (2005). OA impact advantage $=E A+$ (AA) $+(\mathrm{QB})+\mathrm{QA}+(\mathrm{CA})+\mathrm{UA}$. University of Southampton Institutional Repository. Retrieved April 17, 2017 , from https://eprints.soton.ac.uk/262085/.

Harzing, A.-W. (2017). Google Scholar is a serious alternative to Web of Science. LSE Impact of Social Sciences Blog. Retrieved April 17, 2017, from http://blogs.lse.ac.uk/ impactofsocialsciences/2017/03/16/googlescholar-is-a-serious-alternative-to-web-ofscience/.

Irawan, D. E. (2015). WTF: Bagaimana Indonesia ditemukan? SEO for academics. Retrieved April 17, 2017 , from http://dasaptaerwin.net/wp/2015/02/bagai mana-indonesia-ditemukan.html.

Irawan, D. E. (2017a). Open Science Indonesia datasets. https://doi.org/10.17605/ OSF.IO/HXH78.

Irawan, D. E. (2017b). Mengorek jumlah makalah berbahasa Indonesia dalam basis data DOAJ dan hubungannya dengan parameter lainnya dari data Bank Dunia. Retrieved April 17, 2017 , from https://derwinirawan.wordpress.com/2017/ 03/26/mengorek-jumlah-makalahberbahasa-indonesia-dalam-basis-datadoaj-dan-bank-dunia/.

Irawan, D. E., Rachmi, C. N., Irawan, H., Abraham, J., Kusno, K., Multazam, M. T., ..., Aziz, N. A. (2017). Penerapan open science di Indonesia agar riset lebih terbuka, mudah diakses, dan meningkatkan dampak saintifik. Berkala Ilmu Perpustakaan dan Informasi, 13(1), 25-36. https://doi.org/ 10.22146/bip.17054.

JISC. (2016). An introduction to open access. Retrieved April 17, 2017, from https://www.jisc.ac.uk/guides/anintroduction-to-open-access.

Juneman, J. (2009). Aplikasi psikologi positif dalam dunia bisnis. Humanitas: Jurnal Psikologi Indonesia, 6(2), 136-151. Retrieved April 17, 2017, from http://id.portalgaruda.org/?ref=browse\&mo $\mathrm{d}=$ viewarticle \&article $=124048$. 
Modi, H. (2014). Which indexing service is good from the following: Scopus, Thomson Reuters ISI, Google Scholar? What are the advantages and disadvantages of each? ResearchGate. Retrieved April 17, 2017, from https://www.researchgate.net/ post/Which_indexing_service_is_good_fro $\mathrm{m}$ the following Scopus Thomson Reute rs ISI_Google Scholar What are the ad vantages and disadvantages of each.

Nashihuddin, W., \& Aulianto, D. $\overline{\text { R. (2016). }}$ Pengelolaan terbitan berkala ilmiah sesuai ketentuan akreditasi: Upaya menuju jurnal terakreditasi dan bereputasi internasional. Jurnal Pustakawan Indonesia, 15(1-2), 83-98. Retrieved from http:// journal.ipb.ac.id/index.php/jpi/article/view/ 16921.

Rahim, R., Irawan, D.E., Zulfikar, A., Hardi, R., ArlimanS., L., Gultom, E.R, ..., Abraham, J. (2018). INA-Rxiv: The missing puzzle in Indonesia's scientific publishing workflow. Journal of Physics: Conference Series, $\begin{array}{llll}1 & 0 & 0 & 7\end{array}$, 012032.https://doi.org/10.1088/17426596/1007/1/012032.

Shearer, K., Yamaji, K., \& Repanas, K. (2016). Asian open access meeting report. COAR. Retrieved April 17, 2017 , from https://www.coar-repositories.org/ files/Open-Access-Asia-Report.pdf.

Shen, C., \& Björk, B.-C. (2015). "Predatory" open access: A longitudinal study of article volumes and market characteristics. $B M C$ Medicine, 13(1), 230. https://doi.org/ 10.1186/s12916-015-0469-2.
Tennant, J. P., Dugan, J. M., Graziotin, D., Jacques, D. C., Waldner, F., Mietchen, D., ..., Collister, L. B. (2017). A multidisciplinary perspective on emergent and future innovations in peer review [version 1; referees: 2 approved with reservations]. F1000Research, 6 ( 11151 ). https://doi.org/10.12688/f1000research.120 37.1.

Tennant, J. P., Waldner, F., Jacques, D. C., Masuzzo, P., Collister, L. B., \& Hartgerink, C. H. J. (2016). The academic, economic and societal impacts of Open Access: an evidence-based review [version 1; referees: 4 approved, 1 approved with reservations]. F $1000 R$ ese arch, 5 ( $\left.\begin{array}{lll}6 & 3 & 2\end{array}\right)$. https://doi.org/10.12688/f1000research. 8460.1.

Tennant, J., \& Matthias, L. (2017). How to make your research open access? For free and legally. https://doi.org/10.6084/ m9.figshare.5285512.v2.

Tennant, J., \& Mounce, R. (2015). Open research glossary (Version 1 ). https://doi.org/10.6084/m9.figshare. 14820 94.v1.

Viridi, S., \& Yuliarto, B. (2017). Journal writing. In Sharing Session Kamil Pascasarjana ITB. http://doi.org/10.13140/ rg.2.2.12151.83366. 


\section{DAFTAR GAMBAR}

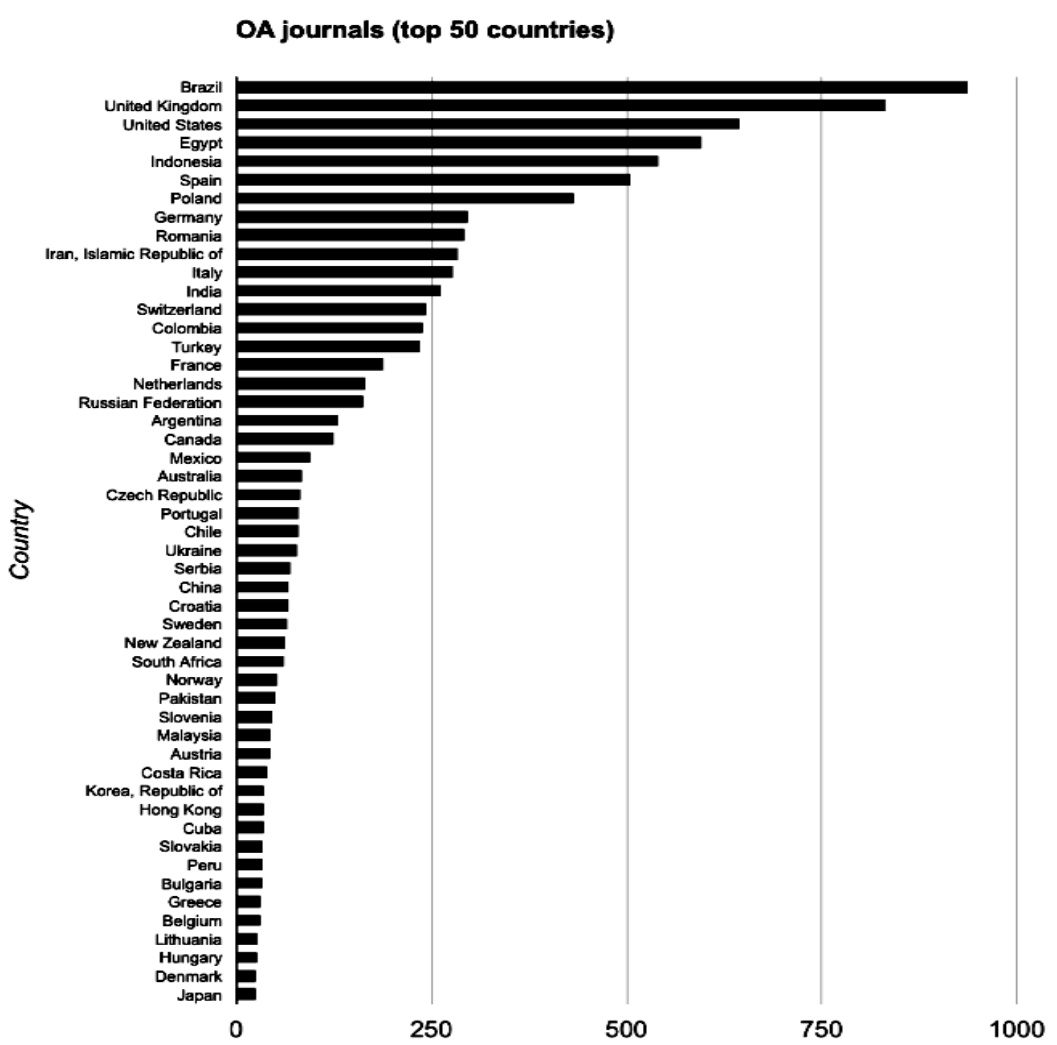

Gambar 1. Jumlah jurnal OA dari top 50 negara (country) (dataset DOAJ diolah oleh Irawan, 2017a)

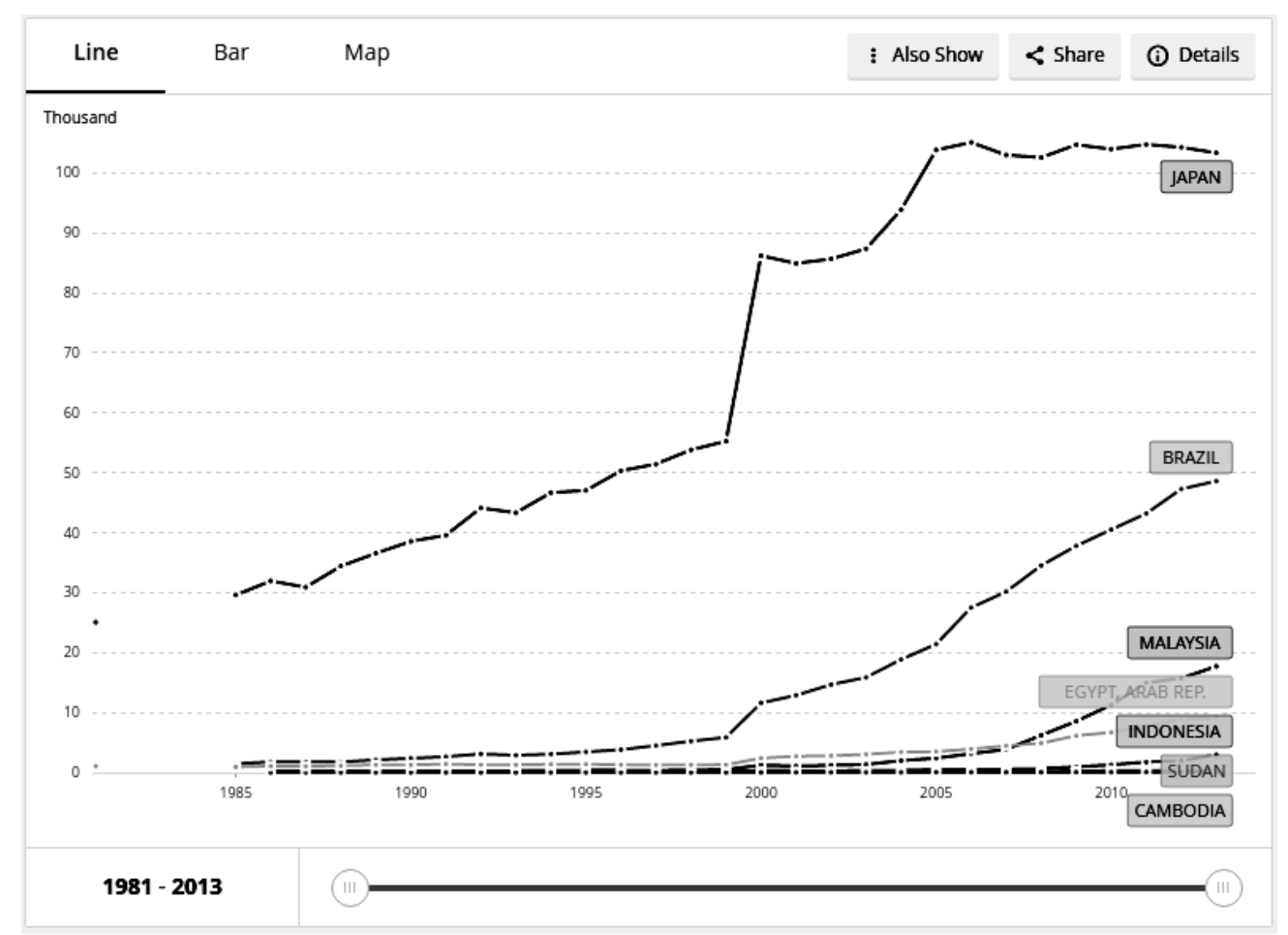

Gambar 2. Jumlah publikasi menurut Bank Dunia untuk beberapa negara terpilih (data diakses tanggal 26-27 Maret 2017) (Irawan, 2017a) 


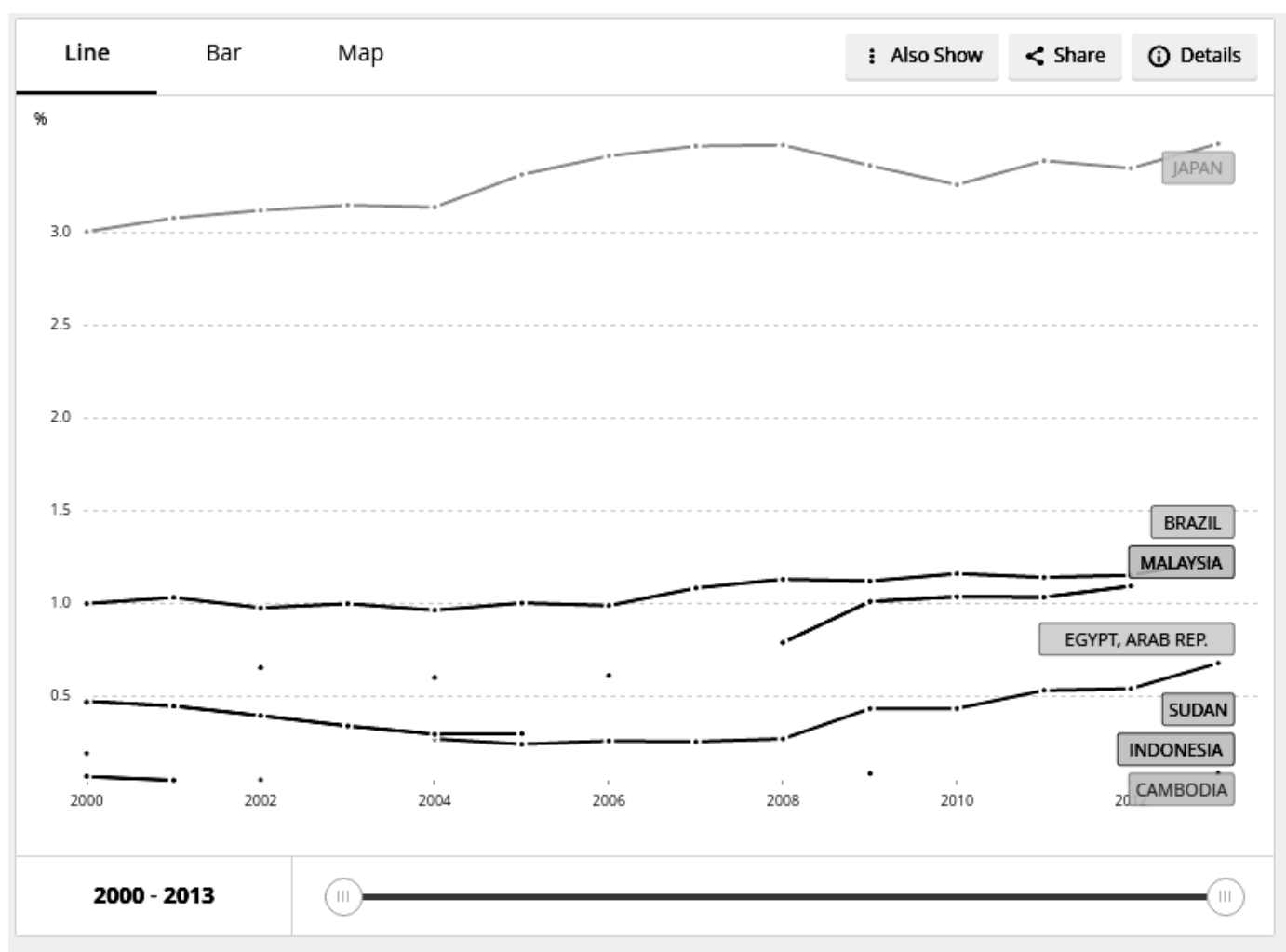

Gambar 3. Persentase dana riset dan pengembangan dari total Gross Domestic Product (GDP) menurut Bank Dunia untuk beberapa negara terpilih (data diakses tanggal 26-27 Maret 2017) (Irawan, 2017a)

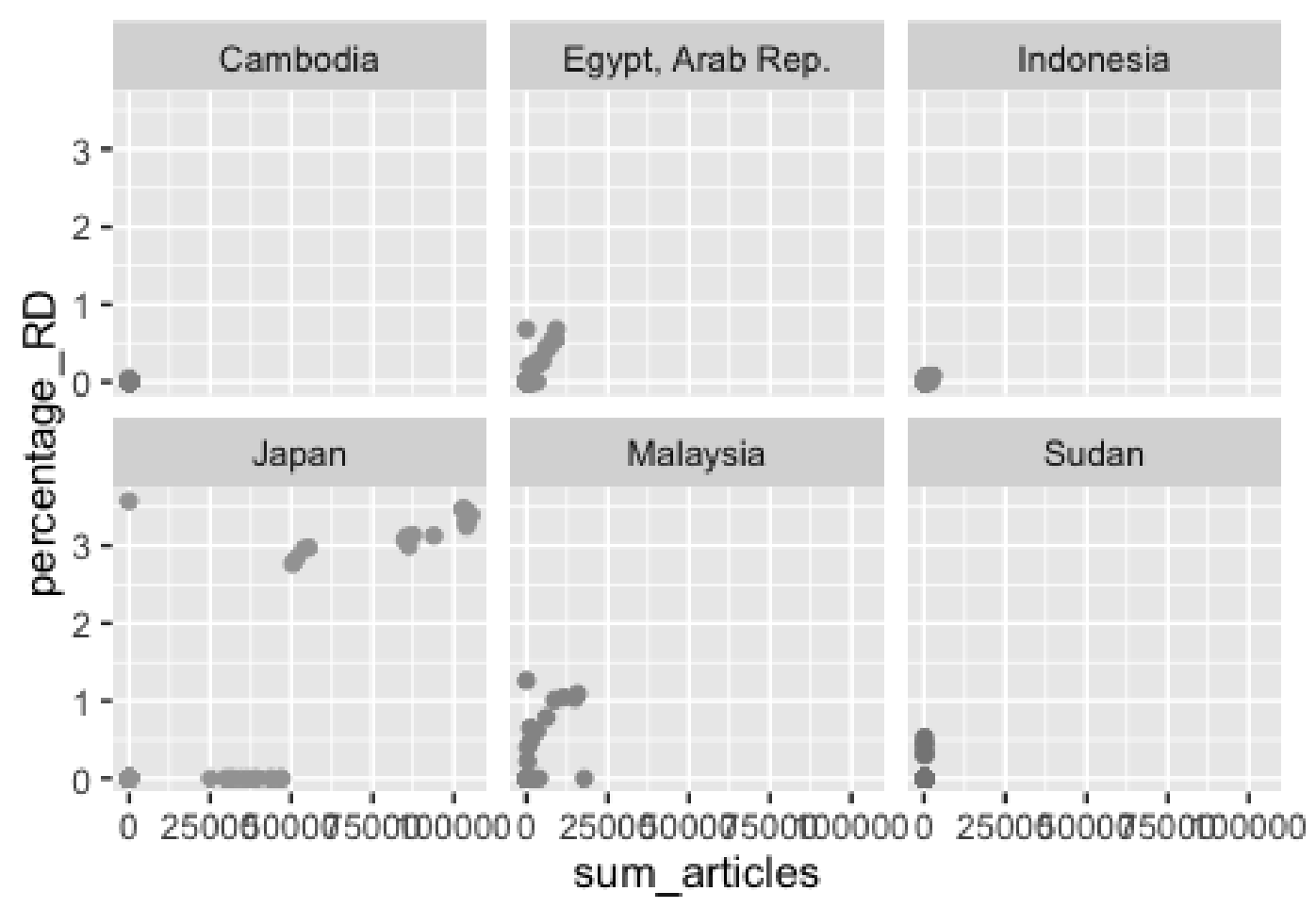

Gambar 4. Jumlah artikel (sum articles) vs persentase dana R\&D (percentage RD) dari total GDP menurut Bank Dunia untuk beberapa negara terpilih (data diakses tanggal 28 Maret 2017) (dataset Bank Dunia diolah oleh Irawan, 2017a) 




Gambar 5. Jumlah artikel (sum articles) vs persentase dana R\&D (percentage_RD) (per 1000 penduduk) menurut Bank Dunia untuk beberapa negara terpilih (data diakses tanggal 28 Maret 2017) (dataset Bank Dunia diolah oleh Irawan, 2017a)

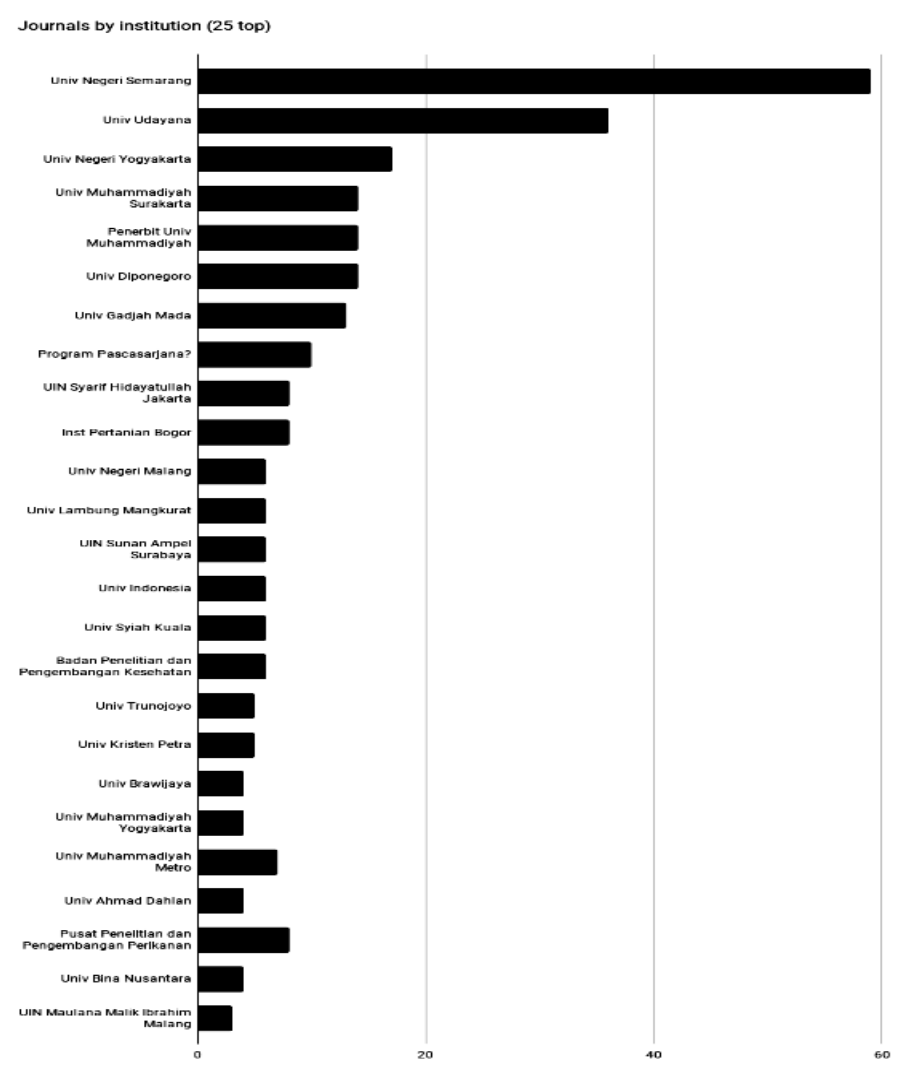

Gambar 6. Jurnal OA dari top 25 institusi (dataset DOAJ diolah oleh Irawan, 2017a) 
Journals by subject (top 25)

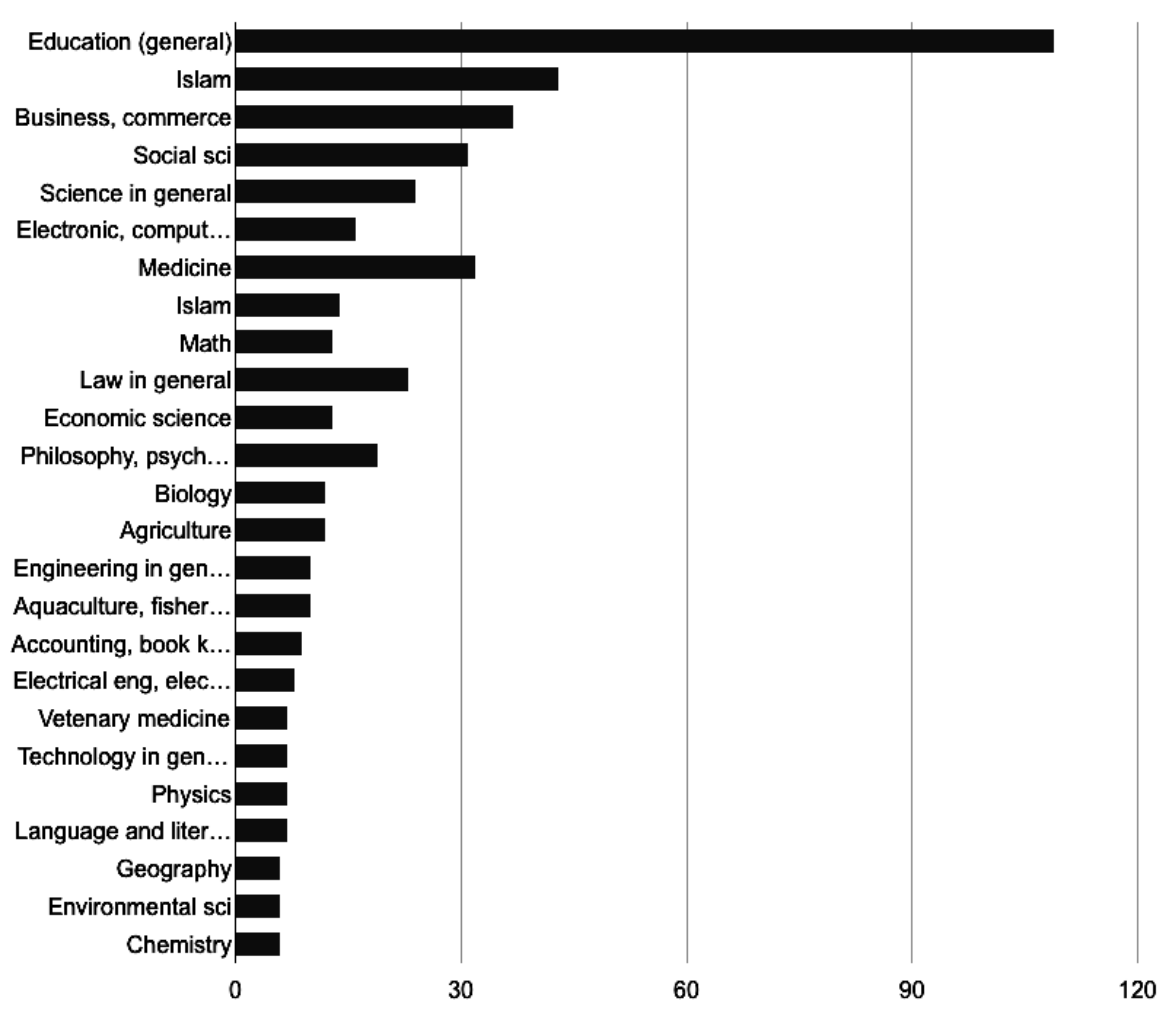

Gambar 7. Jurnal OA berdasarkan bidang ilmu (top 25) (dataset DOAJ diolah oleh Irawan, 2017a) 